would have made an interesting extension of our knowledge; but, when critically examined, the kind of radiation turned out to be for the most part not Röntgen rays, but corpuscular, and to have nothing to do with fluorescence.

Becquerel set himself carefully to examine the kind of penetrating radiation which fluorescent substances exposed to light might be found to emit. Though not finding that for which he sought, he made a discovery of far greater importance.

After giving an account of the recent discoveries in radio-activity, the lecturer dwelt on the present trend of scientific thought; of the tendency to return to discarded hypotheses such as spontaneous generation and the corpuscular theory of light. Our attitude amongst so many conflicting hypotheses should be to admit that any law applicable to concrete objects and established by induction on a basis of experience must be of the nature of a postulate; that we should hold some of the postulates as so well-established that arguments necessitating their overhauling should, ipso facto, to that extent be discredited, and should not receive our encouragement unless supported by new facts. Our endeavours should be to harmonise new facts with the firmly established laws of physics until compelled to look for some higher generalisation.

Reference was then made to some of the wellestablished laws, and to the attempts to construct living matter from artificially combined materials. Life demands energy for its manifestations, and radioactivity may be suggested as a possible source of such energy. It is known that atoms give off energy as they disintegrate; that organic compounds likewise disintegrate and evolve energy, finally becoming inorganic. A decaying heap of refuse represents a close chemical analogy to the physical activity of uraniumone is an affair of atoms, the other of molecules. This stock of energy running to waste seems eligible for guidance. Life has to control this spontaneous disintegration of protoplasmic cells, to regulate the activity of the ganglia in the brain, for instance, or to suspend the disintegration of organic material until some appointed time, and then to direct it along some determined channel. We have yet to discover how life achieves this control. Those who say that life cannot guide material processes unless it is itself a form of energy, and those holding that life cannot act at all unless energy is at its disposal, forget the spontaneous activity of complex organised molecules and the atomic disintegration manifested by radio-activity.

There is a great difference between matter potentially living and actually alive. In the physical universe our power is limited to the movement of matter; after that, all that happens is due to the properties of matter and its ethereal environment. If potentially living matter is ever artificially made by placing things in juxtaposition and bringing physical resources to bear upon the assemblage, then it may become alive. If this last step be taken, it will be because something beyond matter, something outside the region of physics and chemistry, has stepped in and utilised the material aggregate provided. Only in this sense did the lecturer consider that the artificial incarnation of life would be possible. Some day life may appear under observation, but it will not be manufactured, any more than radium or radio-activity has been manufactured.

Sir Oliver Lodge spoke of the tendency of presentday science to materialise the invisible, quoting, among other examples of this, the fact that plague, which in olden times was attributed to such mysterious causes as a conjunction of the planets, the iniquities of the Jews, \&c., is now known to be due to a minute vegetable parasite living on the fleas of rats.

NO. 2243, VOL. 90]
The scientific life and work of Antoine Henri Becquerel were then dealt with, and an account given of his chief discoveries. A vote of thanks to Sir Oliver Lodge, proposed by Sir William Crookes, O.M., F.R.S., seconded by Prof. Henry E. Armstrong, F.R.S., and supported by the president, was briefly acknowledged by the lecturer.

\section{THE RELATIONS BETWEEN VARIOUS SOLAR PHENOMENA.}

TWO papers recently published in the Comptes rendus (No. 10, September 2, and No. 12, September I6), by Prof. Ricco and M. Deslandres respectively, contain several very important statements, concerning the interrelations of such solar phenomena as filaments, alignements, prominences, spots, \&c., which no student of solar physics can afford to neglect, and which we briefly summarise below.

Prof. Ricco, having studied his valuable records of limb prominences and also those published by Wolfer, finds that the prominences frequently appear in the same position on the sun's limb for several consecutive days, and so must form files of prominence activity across the disc, strongly resembling M. Deslandres's filaments and alignments; he also finds limb prominences recorded at the time and in the positions indicated by $M$. Deslandres's filaments and alignments. He concludes that there is an indisputable connection between the two sets of phenomena. With sun-spots, however, he finds no connection with the filaments and alignments. But in his paper M. Deslandres considerably modifies this latter conclusion of Prof. Ricco's, and states that there is a general con. nection, the several phenomena obviously belonging to one system and reacting on each other.

M. Deslandres, in order to make the investigation more precise, gives further important results concerning the filaments and alignments shown on his wonderful series of photographs. $\mathrm{He}$ agrees that a prominence on the limb generally means a filament or alignment joining the limb at that point. The relation between the two sets of phenomena is confirmed. Further, he differentiates more clearly between filaments and alignments, the former being a special case of the latter, which cover much greater lengths. Alignments vary in intensity from feebly bright to very dark, and then merge into filaments which are exceptionally black and well defined. The alignments are frequently bordered, diffusely, with parallel bright lines, whereas the filaments are clearlycut lines. Filaments are found on both the "hydrogen" and the "calcium" photographs, most strongly marked on the former, whereas alignments are, in general, only found on the "calcium" photographs. The brightest prominences occur at the ends of these bright companions of the alignments, and are, therefore, as Prof. Ricco also points out, not symmetrically placed with regard to the central dark alignment. Prof. Ricco suggests that this asymmetry is due to the fact that while the prominences are emission, the alignments are absorption, phenomena, and thus the two things probably represent activity in different layers of the solar atmosphere.

M. Deslandres suggests that the restriction of alignments to the "calcium" photographs, whereas the filaments are better shown on the "hydrogen" plates, may be due to the fact that the filaments probably exist at higher levels, not so readily reached by the calcium vapours. He also suggests that those eruptive prominences not connected with spots are intimately connected with filaments, and in his radial-velocity 
researches has found that these two phenomena are alike in showing an ascensional radial velocity.

The importance of these researches is obvious, and the results likely to accrue from the simultaneous study of the forms and velocities of the various features most valuable, but, as $M$. Deslandres points out, it will only be possible to state general and definite laws when continuous and complete observations have extended over at least one undecennial period of solar activity.

\section{THE SIGNIFICANCE OF LIFE TO THE $O M A H A .^{1}$}

F OR twenty-nine years Miss Alice Fletcher has been studying the Omaha, and her monograph of the tribe is now published in the twenty-seventh Annual Report of the Bureau of American Ethnology. Her collaborator for most of this time was Mr. Francis La Flesche (the son of Joseph La Flesche, former principal chief of the tribe), who in his boyhood witnessed some of the ceremonies described in the memoir, which were later explained to him by his father and by the old men who were the keepers of these ancient rites and rituals. When Miss Fletcher first went to live among the Omaha, the tribe had recently been forced to abandon hunting owing to the sudden extinction of the herds of bison. All the men and women had participated in the old life, many of the ancient customs were practised, and much of the aboriginal life still lingered. The environment was changing quickly; all that they formerly had relied on as stable had been swept away; the bison, which they had been taught was given them as an inexhaustible food supply, had been destroyed by agencies new and strange; even the wild grasses that had covered the prairies were changing. Great unrest and anxiety had come to the people through the Government's dealings with their kindred, the Ponca tribe, and fear haunted every Omaha fireside lest they, too, be driven from their homes and the graves of their fathers. The future was a dread to old and young. Thanks to the strenuous efforts of Miss Fletcher on their behalf, a law was enacted in 1882 granting lands in severalty, and prospective citizenship. In 1802 the Omaha were reduced to about 300 by smallpox; twenty-seven years later they were said to number 1900 ; in 1906 the population of the tribe was 1228 . The past is overlaid by a thriving present. The old Omaha men and women sleep peacefully in the hills while their grandchildren farm beside their white neighbours, send their children to school, speak English, and keep bank accounts.

"In the account here offered," Miss Fletcher says, " nothing has been borrowed from other observers; only original material gathered directly from the native people has been used, and the writer has striven to make, so far as possible, the Omaha his own interpreter." The most important previous accounts of the tribe are the Rev. J. Owen Dorsey's "Omaha Sociology," published in the third Annual Report of the Bureau in 1884 , which ever since has been largely quoted, and his paper on "Omaha Dwellings, Furniture and Implements" (the thirteenth Report, 1896). It will be found that there are many discrepancies between Dorsey's and Miss Fletcher's statements. For example, Dorsey says that the Black Shoulder clan were originally bisons ("buffaloes") and dwelt under the surface of the water, but Miss Fletcher writes, "no Omaha believes that his ancestors ever were elk, or buffalo, or deer, or turtle, any more than

1 Twenty-seventh Annual Report of the Bureau of American Ethnology to the Secretary of the Smithsonian Institution, rgo5-6. Pp. 672. (Washington: Government Printing Office, rgru.)

NO. 2243 , VOL. 90] that they were the wind, the thunder, or the sky" (p. 6oI).

As has just been stated, Miss Fletcher gives us only first-hand matter, which she has carefully sifted and verified so far as possible. She evidently did not like to criticise or correct Dorsey's statements; there can, however, be little hesitation by students which account they should follow when discrepancies occur. On account of the great changes that have taken place in the material, social, and religious life of the Omaha it is improbable that anything of importance can be gleaned by future workers, and much that Miss Fletcher describes will then be unobtainable. Her monograph, the result of arduous and protracted toil, is the record by a field worker of wide sympathy and insight of investigations which were begun at the critical time of incipient disintegration and while the old knowledge was still fresh in the minds of the people. Some American ethnologists even go so far as to say that she reads into the native mind ideas that it does not contain, but the more we learn about the North American Indian the more apparent it is that he is imbued with a rare spirituality, and it is a common experience that one field observer will discern what another cannot see, as an old writer has said, "The natural man receiveth not the things of the Spirit of God : for they are foolishness unto him : neither can be know them, because they are spiritually discerned." Doubtless Miss Fletcher is content to leave this matter to the arbitration of the intensive study of the religion of allied tribes.

The legendary home of the Omaha and cognate tribes was in the east, "near a great body of water," and the legend gives an interesting account of cultural evolution, due partly to invention and partly to borrowing from other tribes. All children passed through a ceremony of turning, which was directly related to the wind, earth, and fire, whereby it was introduced to the tribe. Later a lock of the boy's hair was cut off and given to Thunder; thereby the life of the child was given into the keeping of the god that controlled the life and death of the warrior. The next stage in the life of an Omaha youth was marked by the rite introducing him to individual life and to the supernatural. Four days and nights the youth was to fast and pray, then in a trance he saw an object which was his personal connection with the universe, by which he could strengthen his spirit and his physical powers. There were societies the membership of which was made up of men who had had visions of the same object. The sequence of rites began at birth, with the announcement to all created things that a new life had come into their midst; when the child had acquired ability to move about of its own volition, its feet were set in the path of life, and it entered into membership of the tribe; the entrance into manhood required voluntary effort, and by prayer and fasting the man came into direct and personal relations with the supernatural.

Miss Fletcher states that "the tribal organisation was based on certain fundamental religious ideas, cosmic in signifirance." The real division of the tribe was based on the dual division in nature; each contained several "gentes," which in their turn were divided into "subgentes. ... The Omaha gens was a group of exogamous kindred who practised a particular rite, the child's birthright to which descended solely through the father; and the symbol characteristic of that rite became the symbol, crest, or "totem' of the gens." A noticeable feature in the book is the large number of prayers and songs, which are given in the native language, with a literal and free translation, and with the musical notation. A considerable space is given to an account of the social and secret societies; the 